\title{
Apuntes sobre líneas estratégicas de Turismo Cultural en la comarca de
}

\section{La Loma}

\author{
Antonio Ortega Ruiz \\ Centro Andaluz de Estudios para el \\ Desarrollo Rural \\ Universidad Internacional de Andalucía \\ Sede Antonio Machado
}

\section{Resumen}

La comarca de la Loma dispone de un importantísimo patrimonio cultural conformado por un legado arquitectónico más que notable centrado fundamental, aunque no únicamente, en el Renacimiento; abundantes restos arqueológicos; manifestaciones culturales de extraordinaria riqueza como la Semana Santa, su tradición cerámica, el olivar y el aceite de

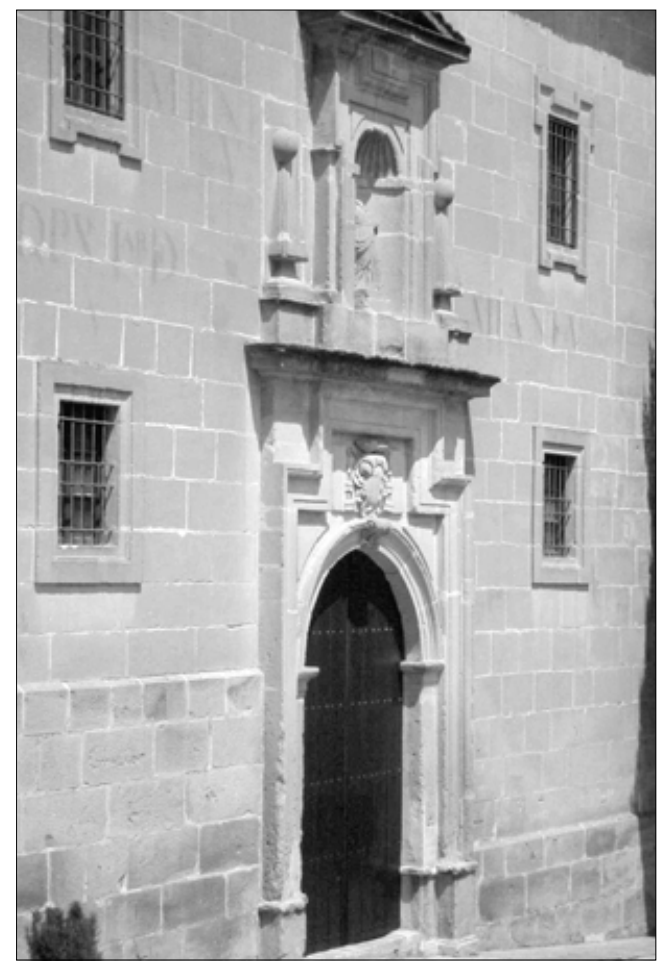

oliva; un medio natural de gran interés, y otros, que avalan la candidatura de las dos localidades más representativas de la comarca, Baeza y úbeda, para ser nominadas Patrimonio de la Humanidad por la UNESCO.

En los últimos años, el patrimonio cultural se está convirtiendo en objeto de atención por su valor como un recurso rentable social, económica y políticamente. Las mayores y más diversificadas posibilidades de ocio contribuyen a extender el interés por el patrimonio cultural como un instrumento lúdico, de entretenimiento y turístico cuyo poder de atracción abre nuevas vías de desarrollo. Pero el patrimonio no es un producto más del mercado. Para que estas potencialidades no devengan en peligros es necesario establecer criterios de uso que se basen en la sostenibilidad, el beneficio social, el mantenimiento de las señas de identidad, la planificación integral y la participación. Desde esos presupuestos, se apuntan algunas propuestas estratégicas para la comarca de La Loma.

\section{Palabras clave}

Patrimonio cultural/ Utilidad Social/ Recurso/ Turismo/ Sostenibilidad/ Señas de Identidad/ Planificación integral/ Participación/ Administraciones Públicas

\section{Panorámica de la comarca de La Loma}

La provincia de Jaén ha sido, y sigue siendo todavía, una gran desconocida tanto para Andalucía como para el resto de España. Con una imagen centrada en la cultura del olivar y las sierras, Jaén viene siendo conocida, fundamentalmente, por sus inmensas extensiones de olivos, por su aceite y por el Parque Natural de las Sierras de Cazorla, Segura y las Villas, destino tradicional de la mayoría de los visitantes de la provincia. Sin embargo, junto al olivar y las sierras se ha mantenido como un reducto poco conocido y 
El patrimonio histórico de Jaén está poco difundido, a falta de un modelo de interpretación y de uso turístico y del establecimiento de unos objetivos concretos y priorizados. A lo que hay que unir una indefinición y falta de planificación institucional que ha facilitado el desarrollo de actitudes muy básicas de utilización del turismo como instrumento de extracción de beneficios económicos y políticos de carácter inmediato

valorado, infrautilizado durante mucho tiempo, un importante Patrimonio Cultural, sobre todo arquitectónico, que de unas décadas a esta parte ha ido adquiriendo un papel cada vez más relevante en el atractivo provincial.

Aunque son muchos y variados los bienes culturales que reúne la provincia (cultura ibérica, castillos, patrimonio etnográfico de las sierras, minero, pinturas rupestres, ...) hasta el momento el referente más conocido en este terreno y que ha llegado a alcanzar los mayores índices de atracción, tanto dentro como fuera de la provincia, es el patrimonio arquitectónico renacentista centrado en el triángulo Jaén-Baeza-Úbeda.

En este contexto, la comarca de La Loma, algunas de cuyas ciudades atesoran lo mejor del patrimonio arquitectónico provincial, está adquiriendo una progresiva importancia como consecuencia del mayor conocimiento y reconocimiento de sus notabilísimos valores culturales, como demuestra la presentación de la candidatura de Baeza y Úbeda para ser declaradas Patrimonio de la Humanidad por la UNESCO. Yacimientos prehistóricos del Neolítico y la Edad del Bronce, restos ibérico-romanos como la muralla ciclópea de Ibros o los vestigios de Úbeda la Vieja, herencias visigóticas como el oratorio rupestre de Valdecanales (Rus), y el importante legado medieval (andalusí y castellano) persistente en sus recintos amurallados, estructuras urbanas y en su tradición oral y escrita, se suman a un conjunto de recursos variados como la Semana Santa, la gastronomía, la artesanía, figuras como San Juan de la Cruz, Andrés de Vandelvira, Antonio Machado, y un especial entorno paisajístico centrado en el valle del Guadalquivir y las cercanas sierras de Cazorla y Segura.

Pero a pesar de la diversidad, el elemento cultural identificativo más sobresaliente del conjunto de la Loma es el configurado por la historia y el legado arquitectónico del Renacimiento. Los conjuntos históricos de Sabiote, Úbeda y Baeza se complementan con la presencia de arquitectura militar de la talla de los castillos de Canena, del mismo Sabiote, o los restos del de Torreperogil, la abundante arquitectura religiosa y una extensa cantidad de bienes arqueológicos.

Este patrimonio cultural ha sido, en general, conocido, reconocido y asumido como propio por parte de la población local, provocando en la mayoría un sentimiento de relación cotidiana con el mismo, creando lo que puede parecer un cierto "chovinismo", una actitud de orgullo por un pasado "ilustre", por una "nobleza", por un "esplendor" perdidos, cuyos vestigios materiales han sido asumidos como parte de una identidad social basada en el pasado histórico. Positivo sentimiento de asunción de unas señas que ha contribuido en gran medida a su conservación y mantenimiento.

A pesar de evidentes pérdidas y atentados (que en algún caso todavía se producen), reformas inadecuadas, descompensaciones en la ordenación o falta de planificación, en la actualidad la mayor parte de los municipios que componen la comarca de la Loma no sufren problemas urbanísticos insolubles o irreversibles: tanto su tamaño, como las actividades económicas dominantes, la actitud de gran parte de la población al tiempo que una progresiva concienciación de las administraciones locales han evitado, salvo casos puntuales, la generación de problemas insalvables. De forma genérica podríamos decir que las localidades de La Loma disponen de conjuntos urbanos sin graves desequilibrios y bastante integrados en su entorno inmediato aunque necesitados de acciones puntuales.

Este conjunto de cualidades, el aumento de las tendencias hacia la "explotación" del Patrimonio Cultural, el progresivo interés de las administraciones locales y provinciales así como de las iniciativas privadas, están contribuyendo en el momento presente al desarrollo de una de las facetas más "de moda" de la puesta en valor del patrimonio cultural de La Loma: la promoción turística.

A pesar de todo ello, la comarca de la Loma podría definirse todavía como un "diamante en bruto", con 
todas las oportunidades y amenazas que ello conlleva. Entre otras cosas, porque el capítulo de deficiencias es todavía notable: la mayoría de las localidades de la comarca se resienten de la falta de una idea concreta de interpretación, de una visión de sus valores patrimoniales y de un cuerpo estructurado sobre qué se quiere hacer, transmitir, usar de ese patrimonio, y de los medios a disponer para alcanzar tales fines. Como consecuencia, la mayoría de estas localidades no tienen planes o proyectos sobre su patrimonio y, menos aún, planes integrales que contemplen desde la conservación al uso. Existe una deficiente oferta cultural y de ocio, agravada por la debilidad de infraestructuras culturales, la falta de equipos humanos y un escaso y desestructurado tejido económico y empresarial que no contribuye a la superación de esta situación.
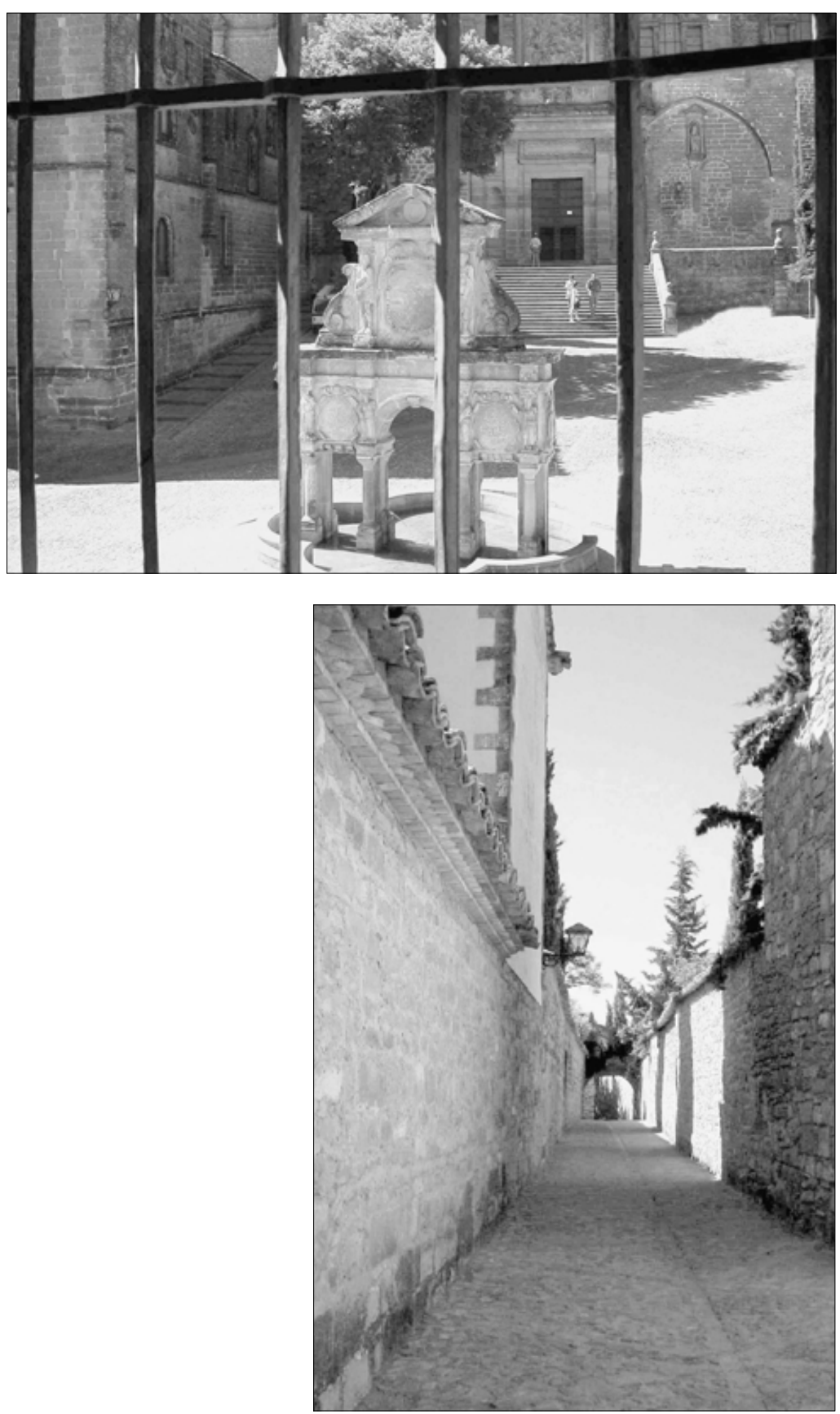

A todo ello, hemos de sumar el papel dominante que ejercen Baeza y Úbeda sobre el conjunto de la comarca: el fuerte poder de atracción de ambas por su poderoso patrimonio histórico-artístico, su mayor población, predominio económico, etc. que ha concentrado en ellas gran cantidad de inversiones, mayores y mejores infraestructuras, una promoción más acentuada; contribuyendo a un paralelo oscurecimiento de los innegables valores de otras localidades de la comarca.

\section{El Patrimonio Cultural y su utilidad turística}

Desde nuestro punto de vista, el Patrimonio Cultural es un recurso más del territorio en que se enmarca, objetivo prioritario para ser recuperado y protegido, pero también importante factor de dinamización y potenciación del desarrollo del que obtener valores añadidos. El patrimonio cultural por todas las circunstancias que en él inciden y que de él se derivan, se constituye como un recurso que puede y debe servir como instrumento para el progreso de los pueblos, ofreciendo respuestas a sus ciudadanos tanto en el aspecto individual como social, espiritual y económico, de formación y de empleo, etc.

Como ya hemos señalado, las crecientes tendencias hacia el uso social, extendido y rentable del patrimonio cultural, lo han convertido no ya en el centro de interés de particulares y grupos reducidos de iniciados (como siempre ha ocurrido), también en sujeto de atención de sectores cada vez más numerosos y de instituciones públicas y privadas, aumentando notablemente su valoración como recurso de ocio y turismo. Precisamente, la relación entre cultura, ocio y turismo se está haciendo en la actualidad tan estrecha que este último se está convirtiendo en uno de los objetivos fundamentales, muchas veces único, del uso del patrimonio cultural. Aquellos lugares que disponen de unos recursos culturales importantes (en general histórico-arquitectónicos), están siendo objeto de actuaciones tendentes a su rentabilización turística. El turismo se ve como una posibilidad de explotación de recursos, de creación de empleo y de desarrollo económico, por lo que instituciones y particulares empiezan a tomar algunas iniciativas, fundamentalmente de promoción y de comercialización de determinados productos.

El turismo es una más de las posibilidades que ofrece el uso de los recursos patrimoniales. Ni es la más importante, ni debemos considerarla la panacea para la salvación de la economía de todos los territorios, ni debe entenderse como la explotación coyuntural de un fenómeno estacional, ni como una fórmula uniforme, universal y de amplio espectro válida en cualquier lugar, tiempo y circunstancia. El valor de uso y de cambio del patrimonio cultural puede, y debe, generar beneficios sociales, entre los que también están los que puede aportar el turismo.

Pero estas actividades pueden llegar a ser tremendamente depredadoras y peligrosas para el patrimo- 
nio: pérdida de identidad, banalización, degradación urbanística, sobreexplotación de recursos, pérdida de calidad de vida local, etc. Hemos de conseguir el equilibrio entre la protección y el uso de nuestro patrimonio como recurso, desde la planificación integral de políticas culturales públicas, intentando superar la dicotomía entre un patrimonio cultural "inútil", caro e improductivo o la mercantilización, venta y "competitividad" económica del mismo.

Por ello, pensamos que el turismo debe ser parte integrante de una política patrimonial integral, nacida desde lo local, que debe coordinar las distintas parcelas (entre otras, el turismo) que en ella inciden. Consecuentemente, la planificación debe ser el instrumento imprescindible a utilizar por los poderes públicos para regular la recuperación, defensa, dinamización, uso y gestión de unos bienes tan especiales que no pueden convertirse en unos productos más del mercado. De lo contrario, se pueden cometer, se están cometiendo, errores graves que pueden condicionar tanto el uso como la existencia de nuestro patrimonio.

Hemos de tener presente que el patrimonio cultural es un recurso único e irreemplazable, con características muy particulares, al que no pueden aplicarse esquemas de mercado puro si no queremos que su conservación y estudio estén únicamente supeditados a la rentabilidad económica y/o política, se caiga en un concepto de modernidad urbana que acabe con las señas de identidad propias arrastradas por los intereses comerciales más uniformizantes, se planifiquen ciudades para los visitantes y no para sus habitantes, se desequilibren socialmente territorios, etc.

En la provincia de Jaén el turismo tiene una vida muy corta. Las características de la misma, interior, rural y de imagen difusa, la han mantenido alejada de los grandes flujos de visitantes hasta tiempos bastante recientes. El turismo como fenómeno de masas nace con el desarrollo de la oferta natural en la sierra de Cazorla, fundamentalmente desde su configuración como Parque Natural de Cazorla, Segura y las Villas. A partir de los ochenta se produce una explosión de promoción, de oferta de servicios, de ampliación de infraestructuras, que convierten al Parque Natural en un territorio de fuerte atracción, aunque bastante estacional, para grandes masas de visitantes. Fenómeno (la promoción, el desarrollo hotelero, la declaración, explotación y gestión del Parque, etc.) que desde nuestro punto de vista necesita una evaluación y análisis críticos de sus resultados.

Sin embargo, la actividad turística en Jaén es todavía escasa, muy estacional y de corta duración; está muy poco diversificada, con productos poco definidos, servicios deficientes y una importante debilidad empresarial. Nuestro patrimonio histórico está poco difundido, a falta de un modelo de interpretación y de uso turístico y del establecimiento de unos objetivos concretos y priorizados. A lo que hay que unir una
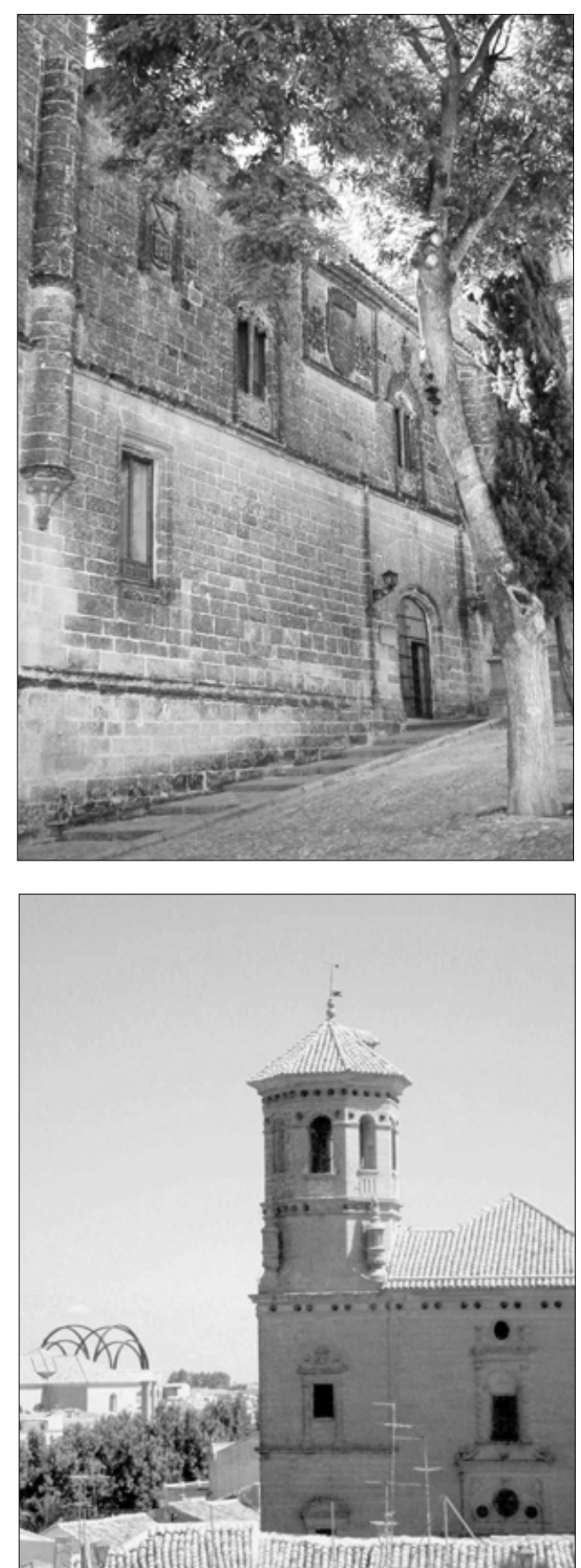

indefinición y falta de planificación institucional que ha facilitado el desarrollo de actitudes muy básicas de utilización del turismo como instrumento de extracción de beneficios económicos y políticos de carácter inmediato. Hasta ahora han primado la improvisación y las acciones individuales e inconexas; el turismo se ha instalado como una moda a la que hay que sumarse, sin una planificación racional, control, ni establecimiento de líneas de actuación. Las entidades privadas y las instituciones públicas se han lanzado a la promoción de las riquezas de nuestra provincia con el único objetivo de atraer al mayor número posible de visitantes.

El único intento de ordenación, aunque muy genérico, se ha producido recentísimamente a través de 
las propuestas que sobre Turismo y Cultura se han discutido dentro del Plan Estratégico de la Provincia de Jaén que inició su proceso de discusión abierta en el año 1999.

Por el contrario, no existen municipios que tengan elaborado un plan de turismo que responda a una previa visión integral de su política cultural, tanto de interpretación como de dinamización; al establecimiento de unas metas determinadas, con unos medios específicos, con mecanismos de gestión y control; que suponga una visión integral de la recuperación y el uso del patrimonio, de las actuaciones urbanísticas, de animación cultural, de ordenación del tráfico y señalización, de promoción, de acción educativa, de coordinación de las iniciativas pública y privada, de planificación turística, etc. ... y que parta de presupuestos de sostenibilidad y de participación de los agentes sociales. Sorprende la ridiculez presupuestaria que algunos Ayuntamientos dedican a las políticas culturales, patrimoniales o de ordenación turística. Asombra la debilidad o inexistencia de estructuras políticas y administrativas, de criterios de actuación y gestión, de servicios de calidad, de un mínimo control sobre visitantes, de su nivel de satisfacción, de conceptos sobre comercialización de la ciudad, de posibles impactos, de coordinación y participación de agentes sociales, etc.

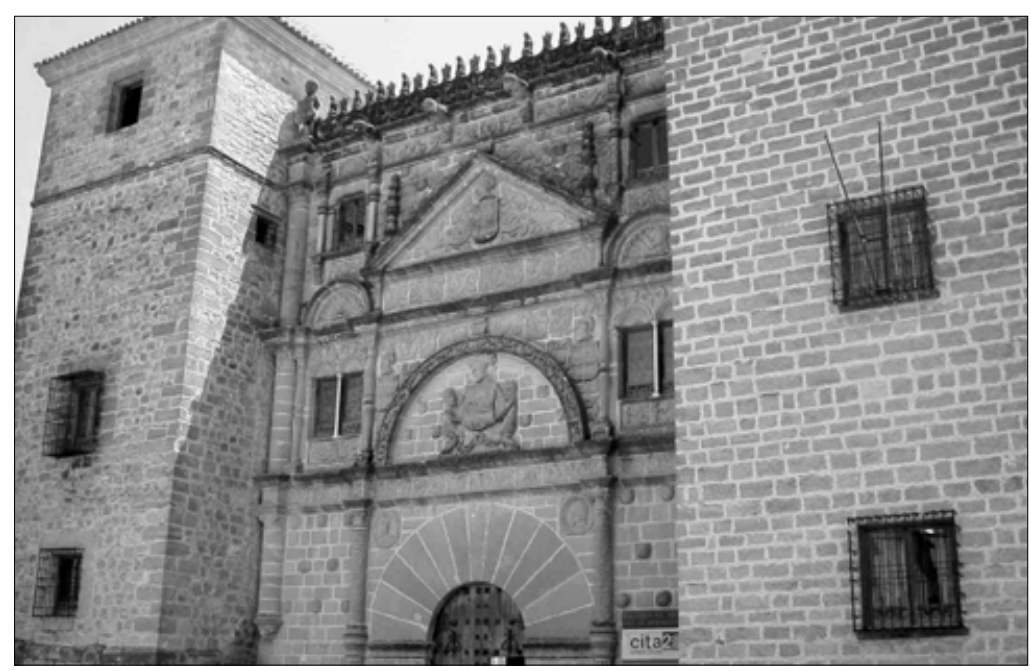

En la comarca de La Loma los evidentes recursos culturales, sobre todo los de carácter arquitectónico, empezaron a despertar en los últimos años el interés de los poderes públicos locales de cara a su promoción turística empujados por la alta valoración que ofrecían los visitantes que "descubrían" la riqueza monumental existente.

Ciudades como Baeza y Úbeda han sido origen de una atracción que ha evolucionado desde el interés romántico de algunos viajeros por ciudades ancladas en el pasado, que hace años se conservaban a duras penas con la pátina del tiempo acumulada como el polvo sobre sus edificios, hasta la actual proliferación de grupos más o menos amplios de visitantes que se detienen lo imprescindible para recorrer solamente "lo más destacado" de una meta volante inserta en una larga etapa a cubrir en el menor tiempo posible, y de la que posiblemente luego no recuerden ni el nombre. Entre un extremo y otro ha estado y está todavía, con todas sus posibilidades aún intactas, el aspecto que debemos defender, perfilar y promover: el disfrute reposado de un patrimonio cultural bien conservado, basado en el urbanismo medieval-renacentista, con atractivos medioambientales y paisajísticos notables, una riqueza folclórica y gastronómica de indudable valor, y un poso cultural impreso en unas señas de identidad bien definidas

Desde hace años, la difusión del fenómeno turístico al tiempo que generaba una nueva y recurrente coletilla en medios políticos y empresariales ha impulsado la comercialización del patrimonio arquitectónico renacentista llegando a la configuración de una Ruta cuyo eje fundamental recorre las ciudades de Jaén, Baeza y Úbeda, y ha extendido una mayor preocupación por el patrimonio y el turismo.

Paralelamente, programas como el de Escuelas Taller, Leader y Proder, etc. han sido un medio para introducir mayores inquietudes y aportar importantes recursos para el cuidado, mejora, y conocimiento del patrimonio cultural y natural, habiendo beneficiado fundamentalmente a Úbeda y a Baeza y contribuido a generar expectativas y servicios relacionados con el uso turístico del mismo. En los últimos años el aumento del número de visitantes se está haciendo más que evidente, de tal manera que la figura del turista ha dejado de ser algo exótico y la presencia de autobuses con grupos nacionales o extranjeros se ha convertido en cotidiana, el número de plazas hoteleras ha aumentado notablemente, y los servicios turísticos complementarios se han extendido y mejorado.

La Loma, además de disponer (como ya hemos señalado anteriormente) de recursos culturales más que suficientes, se encuentra en el momento idóneo para establecer objetivos, criterios y prioridades, perfiles de clientelas, niveles de flujos, mecanismos de control, posibles impactos, etc., antes de tener que solucionar las consecuencias negativas que pudieran producirse a causa de la falta de planificación, la precipitación o la improvisación; pudiendo erigirse en escenario idóneo de primer orden en la aplicación de políticas patrimoniales y turísticas ordenadas, rentables y sostenibles. EI proyecto elaborado para la presentación de la candidatura de Baeza-Úbeda como ciudades Patrimonio de la Humanidad podría considerarse, se conceda o no dicho título, un proyecto de arranque válido a desarrollar para la ordenación de políticas patrimoniales, aunque sería necesario completarlo, dotarlo de órganos participativos y extender su radio de acción al ámbito comarcal.

\section{Algunas propuestas estratégicas}

Como ya hemos señalado en más de una ocasión, en los territorios que sobresalen por la calidad y 
cantidad de sus bienes culturales, el turismo debe ser considerado uno más de los recursos utilizables, pero inscribiéndose como una parte de las políticas sobre conservación y uso del patrimonio. Es un error común y muy peligroso desarrollar iniciativas turísticas independientes y ajenas a la planificación de políticas culturales integrales. Por eso, desde nuestro punto de vista, el desarrollo del turismo en la comarca de la Loma debe ser una parte integrante de la planificación de las acciones tendentes a la recuperación, conservación, mejora y puesta en valor de su rico patrimonio cultural.

Es evidente que la mayor dificultad no se encuentra en la elaboración de estrategias que conjuguen la cultura y el desarrollo desde presupuestos de sostenibilidad y originalidad, que la tiene, sino en la puesta en práctica de las mismas. Está claro que hay que partir del establecimiento de unos objetivos, nacidos de un concepto teórico y necesariamente ideológico, de qué es, para qué (y para quién) sirve, y qué queremos hacer con nuestro patrimonio cultural. De ese fundamento básico deben nacer los peldaños configurados por objetivos a medio y largo plazo, formas de alcanzarlos, instrumentos y acciones con que dotarnos, y medios de evaluación.

Pero si tenemos en cuenta que en la actualidad son muchas las administraciones que participan en acciones que inciden en el ámbito cultural; que la colaboración y coordinación entre las mismas no es su virtud más destacada; que existen intereses departamentales y partidistas muchas veces enfrentados; que la iniciativa privada desarrolla sus actuaciones de forma independiente sin tener por qué considerar los intereses generales; que la mayoría de los municipios, receptores últimos de las políticas culturales, no tienen elaborado un proyecto cultural único e integral; que la planificación y la participación no son prácticas extendidas en la vida política y social española; que los intereses económicos y políticos más inmediatos suelen prevalecer sobre los mediatos; que el intervencionismo partidista e incluso personal suele entorpecer y dificultar el trabajo permanente; podremos percibir la dificultad de poner en práctica proyectos estratégicos a medio y largo plazo. A pesar de lo cual se hace absolutamente imprescindible poner los medios para establecer, de la forma más participativa, plural e integradora posible, los criterios estratégicos que encaucen las políticas culturales.

Desde los planteamientos apuntados anteriormente y la alta valoración que merecen los recursos patrimoniales de que dispone la comarca de La Loma, entendemos que no se puede dejar pasar el momento de establecer unos criterios que enmarquen las políticas culturales en la comarca, unas líneas de actuación que permitan (ahora que se está a tiempo) alcanzar los beneficios que puede generar, y evitar los posibles perjuicios que podrían sobrevenir de la improvisación y la falta de ordenación. Independientemente de que ciertos municipios estén realizando un notable esfuerzo y de que alguno está de-
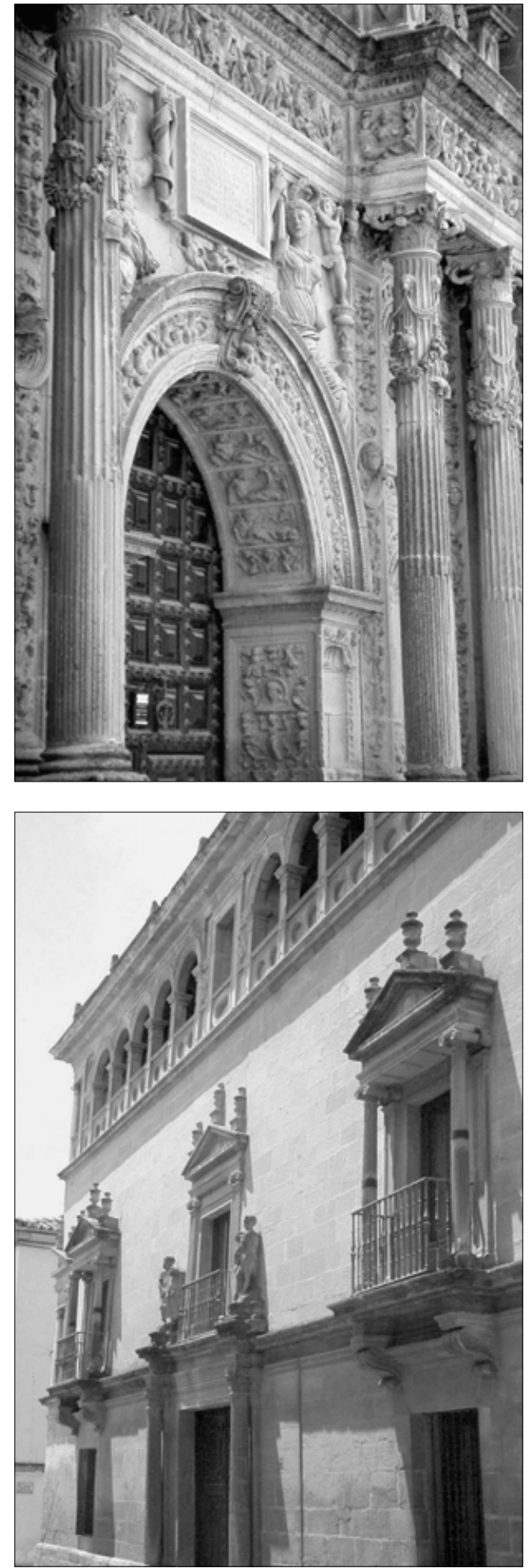

finiendo ya líneas muy concretas de actuación, creemos necesario apuntar algunas consideraciones muy generales sobre lo que podían constituir objetivos estratégicos básicos a desarrollar en la comarca de La Loma.

A pesar de la supuesta evidencia de la aseveración, hay que recordar que el objetivo inicial de las políticas patrimoniales debe ser recuperar, proteger y conservar nuestro patrimonio cultural. Todavía hace falta redoblar esfuerzos de protección, realizar inver- 

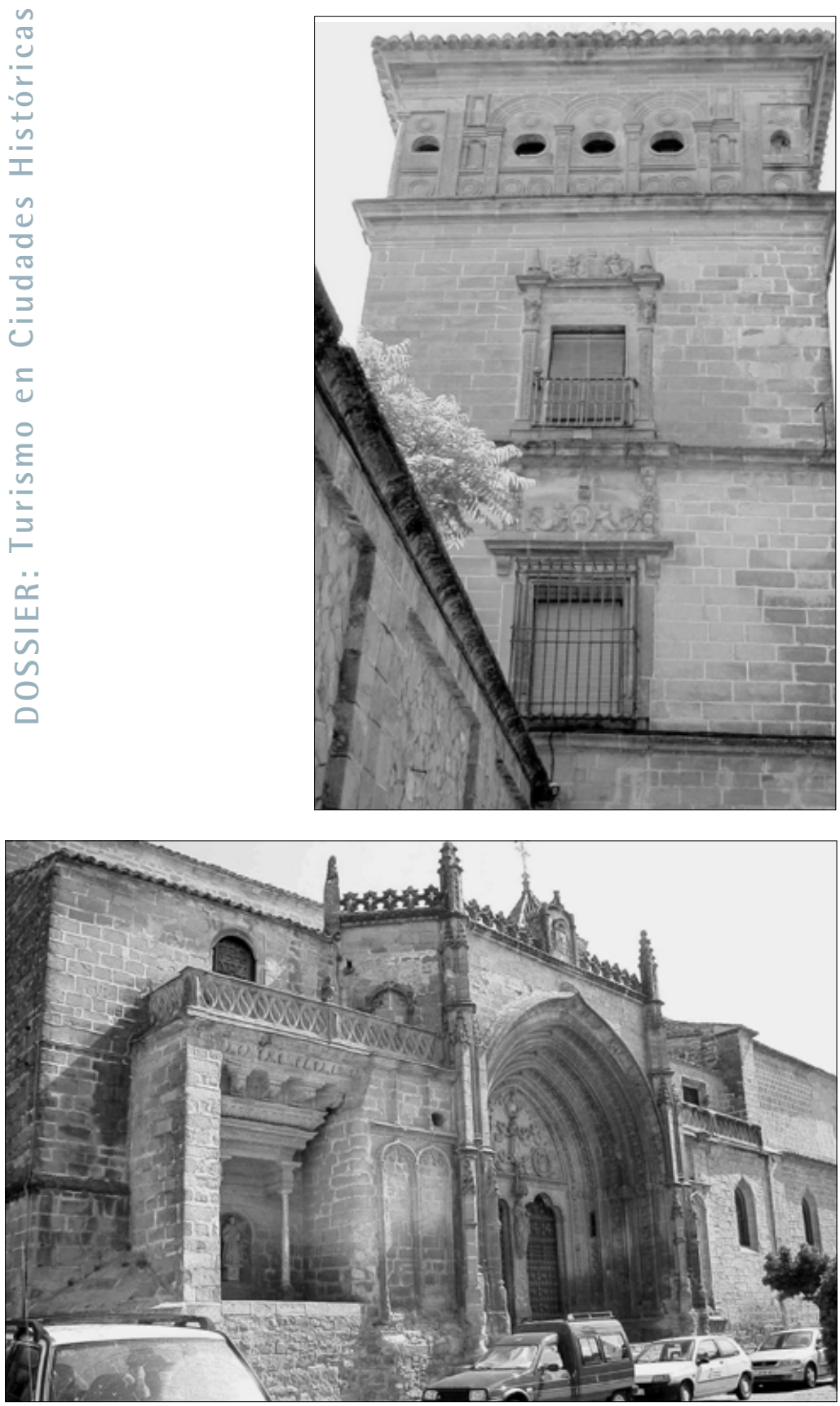

siones para recuperación y rehabilitación de edificios, espacios, yacimientos arqueológicos, ...con el fin de no perder, de mantener, parte del patrimonio que, salvo excepciones, aún necesita un importante apoyo. Esta protección debe traspasar los límites de lo simplemente físico, del objeto en sí mismo, para alcanzar el mantenimiento de las señas de identidad, del entorno, de la singularidad que define las manifestaciones culturales de la zona.

Un segundo objetivo básico es tender a la optimización del uso de nuestros recursos culturales. Uso que debe caminar hacia la perspectiva del desarrollo personal y social: desde el estudio, la investigación, la divulgación y disfrute de esos bienes a la búsqueda de la rentabilización social y económica, la creación de empleo y de riqueza dentro de los presupuestos de sostenibilidad y respeto a la identidad cultural.
Paralelamente debe desarrollarse un proceso de conocimiento de ese patrimonio, para que se asuma, se sienta como propio y, por tanto, sea protegido por la mayor parte de población posible. En ese sentido, se hace necesaria una estrecha relación con el mundo educativo, potenciando el uso y conocimiento didáctico y cultural del patrimonio histórico y natural, y planificando políticas de dinamización cultural ligadas al mismo. Dentro de este apartado, hay que contemplar el diseño de políticas museísticas y de comunicación adecuadas a una idea actual de interpretación, representación y exposición.

Las políticas patrimoniales locales no podrán desarrollarse sin una planificación urbanística rigurosa e integral que tienda al desarrollo armónico de las ciudades, defendiendo no solo los edificios, también las tramas urbanas, sus entornos, las tipologías constructivas, los espacios públicos y los naturales; que tenga en consideración la señalización, el tráfico, etc y que conjugue la protección y el desarrollo, consiguiendo localidades habitables, en primer lugar (y sobre todo) para sus propios vecinos. En aquellos lugares en que existen, hay que aplicar las normativas protectoras de los planes especiales.

Igualmente, hay que rentabilizar los recursos formativos y humanos de que se dispone, incidiendo en la formación de nuevos profesionales mediante programas que tengan en consideración las condiciones, recursos y necesidades de la comarca, optimizando las posibilidades que ofrecen instituciones de empleo (INEM), organizaciones sociales (sindicales y patronales) o educativas (sede Antonio Machado de la Universidad Internacional de Andalucía, Escuelas Taller, Escuelas de Artes).

Vertebrar territorialmente el patrimonio esforzándose por superar los límites locales hacia una visión más integral de La Loma, acogiéndose al lazo unificador del Renacimiento pero diversificando la oferta cultural (castillos, Semana Santa, gastronomía, naturaleza, arqueología...). Todo ello contribuiría a reforzar y consolidar la imagen de la zona, tanto en sus aspectos monumentales como etnológicos y naturales.

Dada la endémica debilidad del sector empresarial, se hace necesario colaborar en la generación de tejido empresarial idóneo en los campos de gestión del patrimonio, turismo, hostelería, etc.

Por último, como uno de los elementos fundamentales y necesarios para el desarrollo de las medidas anteriormente señaladas, es imprescindible la máxima participación social en la fijación de objetivos, elaboración de planes y proyectos y en la gestión. Sin la asunción de ese papel, sin la participación de todos los agentes sociales posibles, institucionales o incluso particulares, implicados en los diversos aspectos que nos ocupan, difícilmente podrán generarse políticas patrimoniales y turísticas sin provocar conflictos. Se deben crear Patronatos, Comisiones, organismos locales que aglutinen a los agentes interesados; e, incluso a nivel comarcal, dotarse de instrumentos coordinadores. 
Como piedra angular sobre la que debe descansar el conjunto de medidas señaladas con anterioridad, se hace necesario profundizar en la cultura de la planificación, la ordenación de objetivos, acciones y medios necesarios; algo desgraciadamente no utilizado en la medida necesaria y que puede ser fundamental para evitar que las debilidades se conviertan en amenazas cumplidas, y conseguir que las fortalezas se traduzcan en oportunidades aprovechadas.

Para finalizar creemos que, dadas las características de los recursos que nos ocupan, la responsabilidad fundamental sobre las políticas relacionadas con el Patrimonio Cultural debe ser asumida por las administraciones públicas; que la iniciativa en la elaboración, desarrollo y gestión de las grandes líneas debe corresponder a las corporaciones locales, provinciales, autonómicas y estatales; bien entendido que la iniciativa privada es imprescindible, tiene sus parcelas específicas y que, como ya hemos dicho anteriormente, deberán ser parte activa en la planificación pública, sobre todo desde el ámbito local. La marea neoliberal, superproductivista, privatizadora y globalizadora que está subiendo de manera no contenida podría ahogar irremediablemente unos valiosos recursos que no solo son patrimonio de todos, especiales y no recuperables, sino que pueden servir para distribuir "rentas" económicas y sociales en beneficio de gentes y territorios.

\section{Bibliografía}

ALONSO IBÁÑEZ, Ma DEL R.: El Patrimonio Histórico. Destino público y valor cultural. Universidad de Oviedo, 1992.

ÁLVAREZ ARECES, M.A.: Patrimonio natural y cultural. ¿DesarroIlo sostenible?. Ábaco n 17-18, 1998.

BASES PARA UNA CARTA SOBRE PATRIMONIO Y DESARROLLO. Consejería de Cultura de la Junta de Andalucía. Sevilla, 1996.

BURBANO, M. El turismo y el patrimonio cultural. Congreso Internacional para la conservación del patrimonio cultural. ICOMOS Ecuador. Quito, 1994.

CHICHARRO CHAMORRO, J.L.: Baeza: notas para una visita. Universidad Internacional de Andalucía. Jaén, 1999.

GARCÍA MARCHANTE, J.S. Y TROITIÑO VINUESA, M.A. (coord.): Vivir las ciudades históricas: recuperación integrada y dinámica funcional. Universidad de Castilla La Mancha-Fundación La Caixa. Cuenca, 1998.

Jaén, Úbeda y Baeza (Ruta del Renacimiento). Everest. León, 1999.

LÓPEZ AGUILETA, I.: Cultura y ciudad. Ediciones Trea. Gijón, 2000

MARCHENA GÓMEZ, M.). (edit.): Turismo urbano y patrimonio cultural. Patronato Provincial de Turismo de Sevilla, 1998.

ORTEGA RUIZ, A.: Úbeda: un paseo por su herencia histórica. Universidad Internacional de Andalucía. Jaén, 2000.
ORTEGA RUIZ, A: El Patrimonio como recurso. ALDABA n 2. Ayunt. de Martos, Agosto 1998.

ORTEGA RUIZ, A.: Algunas consideraciones sobre Patrimonio y Turismo Cultural. ALDABA n 4. Ayunt. de Martos, Agosto 1999.

ORTEGA RUIZ, A.: El Patrimonio Cultural en el Plan Estratégico de Jaén. ALDABA nº 8. Ayunt. de Martos, Agosto 2000.

ROMERO MORAGAS, C.: Patrimonio, turismo y ciudad. Boletín del IAPH, n9. Sevilla, 1994.

ROMERO MORAGAS, C.: Nuevas políticas culturales. Boletín del IAPH, n² 28. Sevilla, septiembre 1999.

V.AA.: Ería. Revista cuatrimestral de geografía. Monográfico dedicado al turismo en las ciudades históricas. $N^{\circ} 47$. Universidad de Oviedo, 1998.

W.AA.: Guía de Úbeda y Baeza. CEDER La Loma, 1995.

W.AA.: La Comarca de La Loma. Fundación Cultural Banesto. Madrid, 1994.

V.AA.: La comarca de La Loma y Las Villas. El Olivo-ADLAS-CEDER. Jaén, 1998.

V.AA.: Patrimonio cultural, territorio y políticas públicas. Revista de Estudios Regionales. Enero-abril 1997. 